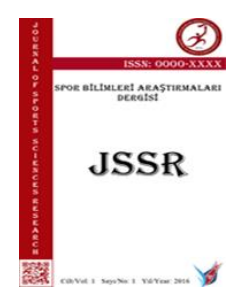

SPOR BÍLİMLERİ ARAŞTIRMALARI DERGISİ

Journal of Sport Sciences Researches

http://dergipark.gov.tr/jssr

ISSN: 2548-0723

\title{
Aktif Statik Germe ve Farklı Dinlenme Aralıklarının İzokinetik Bacak Kuvveti Üzerine Etkisi* $^{*}$
}

\author{
Adil SONGUR ${ }^{1}$, Ebru ÇETIN ${ }^{2 \dagger}$ \\ ${ }^{1}$ Ankara Yıldırım Beyazıt Üniversitesi, Sağlık Bilimleri Enstitüsü. ORCID iD: 0000-0002-1170-1633 \\ ${ }^{2}$ Gazi Üniversitesi, Spor Bilimleri Fakültesi. ORCID iD: 0000-0002-1545-0181
}

$\ddot{\mathbf{O} z}$

Orijinal Makale

Sporcularda aktif statik germenin izokinetik bacak kuvveti üzerine akut etkisini ve bu etkinin germe sonrası dinlenmeye bağlı olarak değişimini araştırmaktır. Gazi Üniversitesi Spor Bilimleri Fakültesinden 19-23 yaş aralığında çeşitli branşlarda (22futbol, 19-voleybol, 16-basketbol ve 4- atletizm) 23 erkek ve 38 kadın sporcu gönüllü olarak çalışmaya dahil edildi. Sağ taraf hamstring, kuadriseps ve dizin diğer kaslarına yönelik her biri altmış saniye süreli dört ayrı aktif statik germe egzersizi belirlendi.. Katılımcılara bu egzersizleri içeren dört farklı protokol [(a) 1sınma, (b) 1sınma + statik germe, (c) 1sınma + statik germe + beş dakika dinlenme, (d) 1sınma + statik germe + on beș dakika dinlenme] uyguland 1 ve her protokolden sonra İsomed 2000 izokinetik cihazı kullanılarak $60 \%$ açısal hızda hamstring ve kuadriseps izokinetik kuvveti ile hamstring/kuadriseps izokinetik kuvvet oranı H/K (R) değerleri kaydedildi. Analizler sonucunda $\mathrm{a}-\mathrm{b}$ ve $\mathrm{b}-\mathrm{d}$ ölçümleri arasında istatistiksel olarak anlamlı sonuçlar tespit edildi. Hem kadın hem erkek hem de toplam (T) analizlerde; (a) ya nazaran (b) ölçüm değerleri anlamlı olarak düşük ( $\mathrm{T}$; hamstring; $\mathrm{a}-\mathrm{b}=+17.8 \mathrm{Nm}$, kuadriseps; $\mathrm{a}-\mathrm{b}=+19.6$ $\mathrm{Nm}$ ) ve (b) ye nazaran (d) ölçüm değerleri anlamlı olarak yüksek bulunmuştur (T; hamstring; b-d=-13.7 Nm, kuadriseps; b-d=-14.3 Nm). Diğer ölçümler arasında ve kuvvet oranlarında $(\mathrm{H} / \mathrm{K})$ anlamlı bir değişiklik bulunmadı $(\mathrm{p}<0,05)$. Bulgular ışığında akut statik germenin kasın izokinetik kuvveti üzerinde negatif bir etki yarattığı, bu nedenle müsabakalardan en az on beş dakika öncesinde statik germenin sonlandırılması veya aktif statik germenin hemen sonrasinda maksimum kontraksiyon gerektirecek aktivitelerden uzak durulması önerilebilir. Öbür yandan farklı germe süreleri, farklı kas grupları ve farklı açısal hızlarda yapılacak ileri çalışmaların gerekliliği göz ardı $\underline{\text { Yayın Bilgisi }}$ edilmemelidir.

DOI: $10.25307 /$ jssr. 393179

Anahtar kelimeler:

Dinlenme aralı̆

germe,

izokinetik

*Bu çalışma, Adil SONGUR'un 2015 yılında tamamlamış olduğu Yüksek lisans tezinden türetilmiştir.

†Sorumlu yazar E-mail: adilsngr@gmail.com, Tel: +905449363934. 


\title{
The Effect of Active Static Stretching and Different Rest Intervals on Isokinetic Leg Strength
}

\begin{abstract}
The aim of the study is to investigate the acute effect of active static stretching on isokinetic leg strength and change of this effect depending on resting after stretching in athletes. 23 male and 38 female athletes from various branches (22-football, 19-volleyball, 16-basketball and 4athletics) participated in the volunteer work at Gazi University Faculty of Sports Sciences between ages 19-23. Four separate active static stretching exercises for hamstring, quadriceps, and other muscles of right knee for sixty seconds each were identified. Participants were administered four different protocols involving the these exercises [(a) warming, (b) warming+static stretching, (c) warming+static stretching + five minutes rest, (d) warming + static stretching+fifteen minutes rest) then hamstring and quadriceps isokinetic strength and hamstring/quadriceps isokinetic strength ratio H/Q (R) values were recorded at $60^{\circ} / \mathrm{sec}$ angular velocity using the Isomed after each protocol. Statistically significant results were obtained between the a-b and b-d measurements as a result of the analyzes. In both male and female and total (T) analyzes; compared with (a), (b) measurement values were significantly lower $(\mathrm{T}$; hamstring; $\mathrm{a}-\mathrm{b}=+17.8 \mathrm{Nm}$, quadriceps; $\mathrm{a}-\mathrm{b}=+19.6 \mathrm{Nm})$ and $(\mathrm{d})$ measurement values were significantly higher when compared to (b) (T; hamstring;b-d=-13.7 Nm, quadriceps;b$\mathrm{d}=-14.3 \mathrm{Nm}$ ). There were no significant differences between other measurements and power ratios $(\mathrm{H} / \mathrm{Q}) \quad(\mathrm{p}<0.05)$. It is suggested that the acute static stretching has a negative effect on the isokinetic strength of the muscle by findings, so it is advisable to terminate the static stretching at least fifteen minutes before the competition or to avoid activities requiring maximum contraction immediately after active static stretching. On the other hand, different stretching times, different angular velocities and the need for new work to be done with different muscle groups should not be overlooked.

Original Article

Article Info

Received: 10.02 .2018

Accepted: 22.06 .2018

Online Published: 30.06 .2018
\end{abstract}

\section{GíRiş}

Isınma ve gerdirme egzersizlerinin, sporcuların fiziksel aktiviteden önce kas iskelet sistemlerini aktiviteye hazırlama aracı olarak kabul edildiği aynı zamanda sakatlanma ve performans üzerine muhtemel etkileri nedeniyle de uygunluk ve egzersiz isınmalarının önemli bir parçası olduğu ifade edilmektedir (Siatras ve diğ., 2003). Statik, dinamik ya da proprioseptif nöromusküler fasilitasyon (PNF) germe teknikleri kullanılarak yapılan gerdirme egzersizlerinin eklem hareketliliğini arttırmaya pozitif etkilerinin olduğunu, hareketlilik artışının kas sakatlıklarının azalmasıyla sonuçlandığını ve daha iyi bir sportif performansa neden olduğunu destekleyen çalışmalar mevcuttur (Ardıç, 2014; Rodenburg ve diğ., 1994; Sady ve diğ., 1982; Shelloc ve Prentice, 1985). Statik germe, hedef kas veya kas gruplarının, hafif rahatsızlık hissedilecek ancak ağrı oluşturmayacak noktaya kadar gerilip elde edilen pozisyonun belli bir süre korunması ile gerçekleştirilir (Carvalho ve diğ., 2009). Dinamik germe eklem hareket açıklığı içerisinde, yavaş ve kontrollü yapılan sallanma hareketleridir. Gerilecek vücut bölümünün gittikçe artan hareket sınırı salınımları ile tam eklem hareket açıklığına ulaştırılması hedeflenir (Appleton, 1998). PNF ise tam bir germe türü olmasa da, maksimum statik esneklik için pasif germe ve izometrik germeyi birleştiren bir yöntemdir (Appleton, 1998). Hedef kas grubunun hem kasılmasını hemde gerilmesini içerir (Walker, 2013). Bir çalışmada 1sınma ve germe egzersizlerinin kas, tendon ve bağların viskozitesini azaltabildiği, bunun sonucunda eklem hareket genişliğini artırarak kas ve eklem yaralanmalarını azalttığ 1 belirtilmiştir (Shelloc ve Prentice, 1985). Kassal esnekliğin artması ile performansın artacağı ve şiddetli egzersizler sırasında sakatlık riskinin 
Songur, A., ve Çetin, E. (2018). Aktif statik germe ve farklı dinlenme aralıklarının izokinetik bacak kuvveti üzerine etkisi. Spor Bilimleri Araştırmaları Dergisi, 3(1), 85-96.

azaltılabileceğinden bahsedilektedir (Smith, 1994). Genellikle germe egzersizleri birçok ders kitabında, kas ağnılarından ve yaralanmalardan korunmayı veya performansı geliştirmeyi amaçladığı iddiasıyla önerilmektedir (Rubini ve diğ., 2007). Egzersiz öncesi 1sınmanın bir parçası olarak hafif aerobik koşu sonrası germe egzersizleri yapmak kabul gören ve tavsiye edilen bir olgudur (Power ve di $\breve{g} ., 2004)$.

Ancak bu alan üzerinde giderek çoğalan araştırmalar germe egzersizlerinin etkileri konusunda daha detaylı ve de farklı sonuçlar gözlemlemektedir. Statik germenin esneklik üzerine olumlu etkileri görülmesine rağmen maksimal kuvvet ve patlayıcı kuvvet üzerinde negatif etkisi olduğunu söyleyen çalışmaların yanında değişiklik olmadığı sonucuna varan çalışmalar bulunmaktadır (Paoadopoulos ve diğ., 2005; Rubini ve diğ., 2007; Sekir ve diğ., 2010; Siatras ve diğ., 2008; Winke ve diğ., 2010). Germe egzersizlerinin performansa olan etkisini araştırmak amacıyla yapılan sistematik bir derleme çalışmasında, germe egzersizlerinin akut dönemde kuvvet ve sıçrama yüksekliğinde bir gelişme yaratmadığı, buna karşın düzenli yapılan germe egzersizlerinin ise kuvvet, sıçrama yüksekliği ve koşma hızında gelişmeye neden olduğu sonucuna varılmıştır (Shrier, 2004). On üç kadın ve on altı erkek sporcu üzerinde yapılan başka bir çalışmada ise 3 dakikalık diz fleksiyonu statik germe protokolü öncesinde ve sonrasında farklı günlerde olacak şekilde 60 ve 210 derece açısal hızlarda ölçümler alınmış ve statik germenin esnekliği arttırdığ 1 ve aynı zamanda maksimal izokinetik kuvvette anlamlı bir değişikliğe neden olmadığı sonucuna varılmıştır (Winke ve diğ., 2010). On altı kadın sporcu üzerinde yapılan benzer bir diğer çalışmada statik germenin dikey sıçrama performansına olumsuz bir etkisinin olmadığı sonucuna varılmıştır (Unick ve diğ., 2005).

Son yıllarda statik germe egzersizlerinin maksimal izokinetik tork üretimi üzerine olumsuz etkisinden bahsedilmektedir (Paoadopoulos ve diğ., 2005). Beş gruba ayrılmış elli katılımcı üzerinde yapılan ve statik germenin süresinin kuadriseps izokinetik kuvveti üzerine etkisini araştıran bir çalışmada, 30 saniyenin üzerinde yapılan statik germenin izokinetik kuvveti düşürdüğü ve maksimal kuvvet gerektiren performanslardan hemen önce yapılmaması gerektiği sonucuna varılmıştır (Siatras ve diğ., 2008). On altı sprinter üzerinde yapılan bir çalışmada statik germenin 20 metre koşu süresinde uzamaya neden olduğu dolayısıyla performansa olumsuz etkisi olabileceği sonucuna varılmıştır (Nelson ve diğ., 2005). Başka bir çalışmada ise; maksimum kas kuvvet dayanıklılı̆̆ gerektiren herhangi bir performans öncesinde bir kas grubunun ağır statik germe egzersizlerinden kaçınılması önerilmiştir (Kokkonen ve diğ., 2005). Birçok branştan on elit kadın atlet üzerinde yapılan başka bir çalışmada ise performansı arttırmak için ısınma esnasında dinamik germenin statik germeye ya da hiç germe yapmamaya nazaran daha etkili olduğu sonucuna varılmıştır (Sekir ve diğ., 2010). Kriterlere uyan 106 makalenin incelendiği ve statik germenin maksimal kas performansı üzerine etkisinin araştırıldığı sistematik bir çalışmada, 45 saniye ve altındaki germenin kas gücünü ve hıza bağlı performansı düşürmediği ve 1sınma sırasında uygulanmasında bir risk teşkil etmediği ancak daha uzun germe sürelerinin performansta azalmaya sebep olabileceği sonucuna varılmıştır (Kay ve Blazevich, 2012). Statik germenin izokinetik kuvvet üzerine etkisinin incelendiği bir diğer çalışma sonucunda statik germenin açı tork eğrisinde düzleşmeye yol açabileceği, bunun da tepe kuvveti, kuvvet üretimini ve kas aktivasyonunu düşürebileceğini belirtilmiştir (Cramer ve diğg., 2007). McBride ve arkadaşları 
(2007) yaptıkları çalışmada aynı kas grubuna yapılan 3 tekrarlı 30 saniye(sn) süren statik germenin birçok eklemin yer aldığı izometrik skuat hareketinin sonucunu etkilemediğini, ancak tek eklemin yer aldığı diz ekstansiyon hareketinin sonucunda üretilen kuvveti olumsuz yönde etkilediğini belirtmişlerdir. Bir diğer çalışmada da statik germenin patlayıcı kuvvet ve sıçrama performansı üzerinde negatif etkileri olduğu sonucuna varılmıştır (Young ve Behm., 2003).

Literatürde yer alan çalışmalar genel olarak incelendiğinde yoğunlukla statik germe egzersizlerinin farklı parametrelere etkileri ve ya uygulanan germe süreleri arasındaki farklılıkların etkileri üzerine olduğu söylenebilir. Ancak statik germe uygulamasının etkisinin ne kadar sürdüğü ve ısınma periyodu sırasında nasıl konumlandırılması gerektiği hakkında çalışmalara rastlanmamıştır. Bu çalışmanın amacı; aktif statik germenin izokinetik kuvvet üzerine akut etkisinin ne olduğu ve varsa eğer bu etkinin ne kadar süre devam ettiğini saptayabilmektir.

\section{YÖNTEM}

\section{Araştırma Modeli}

Araştırma modeli çapraz randomize olarak tasarlanmıştır.

\section{Çalışma Grubu}

$\mathrm{Bu}$ araştırma Gazi Üniversitesi Biomekanik ve Performans Analizi Laboratuvarında gerçekleştirildi. Araştırmaya Gazi Üniversitesi Spor Bilimleri Fakültesinde öğrenim gören, çeşitli spor branşlarında (22-futbol, 19-voleybol, 16-basketbol ve 4-atletizm) aktif spor yapan 61 (38 kadın ve 23 erkek) gönüllü katılımcı dahil edildi. Tüm katılımcılara her biri ayrı ve ardışık olmayan günlerde sırasıyla aşağıdaki dört farklı protokol uygulandı.

\section{Protokoller}

a: Beş dakika hafif aerobik koşu + izokinetik kuvvet ölçümü

b: Beş dakika hafif aerobik koşu + aktif statik germe egzersizi + izokinetik kuvvet ölçümü

c: Beş dakika hafif aerobik koşu + aktif statik germe egzersizi + beş dakika dinlenme + izokinetik kuvvet ölçümü

d: Beş dakika hafif aerobik koşu + aktif statik germe egzersizi + on beş dakika dinlenme + izokinetik kuvvet ölçümü

Tüm katılımcılara protokolün içeriği anlatıldı ve her uygulamadan önce egzersizler gösterildi. İzokinetik ölçüm esnasında her ölçümden önce beş tekrarlı alıştırma yaptırıldı. En yüksek performansı ortaya çıkarmak için uygulama sırasında katılımcılar görsel ve sözel olarak teşvik edildi.

\section{Egzersizler}

Uygulanan protokollere dahil edilen germe egzersizleri temel olarak sağ bacak diz bölgesi kaslarına yönelik 4 farklı statik germe egzersizinden oluşturuldu. Her egzersiz 30'ar saniyeden 2 set şeklinde uygulandı. Uygulanan aktif statik germe egzersizleri sirasıyla şöyledir: 
1. Iliotibial bant germe: ayakta duvara yan duruş pozisyonunda iken sol bacak să̆ bacă̆ın önünden çaprazlanır ve yavaşça kalça duvara yaklaştırılıp ağrı sinırında tutulur (Fredericson ve diğ., 2002). Otuz saniye statik olarak durduktan sonra 10 saniye gevşeyip hareket tekrarlanır

2. Kalça-diz adduksiyon germe: Dizüstü pozisyonunda iken să̆ bacak yana doğru uzatıllir ve ăgrt sintrinda statik beklenir (Nelson ve Kokkonen., 2007). Otuz saniye statik olarak durduktan sonra 10 saniye gevșeyip hareket tekrarlanir.

3. Diz ekstansiyon-kalça fleksiyon-dorsifleksiyon germe: Sol bacak önde olacak şekilde yarım dizüstü pozisyona gelinir. Să̆ elle să ayak sırtından tutulur ve topuk kalçaya doğru çekilirken ăgrl sinirına gelene kadar gövde öne götürülü (Paoadopoulos ve diğ., 2005). Otuz saniye statik olarak durduktan sonra 10 saniye gevşeyip hareket tekrarlanir.

4. Diz fleksiyon-kalça ekstansiyon-plantar fleksiyon germe: Uzun oturma pozisyonuna gelinir ve sol diz fleksiyona ve eksternal rotasyona getirilir. Elle sağ ayak bileğine dokunmaya çalışır gibi gövde öne doğru uzatıllr ve ayak bileği dorsifleksiyona zorlanır (Paoadopoulos ve diğ., 2005). Otuz saniye statik olarak durduktan sonra 10 saniye gevşeyip hareket tekrarlanır

\section{Veri Toplama Aracı}

Her bir protokolün uygulanmasından sonra, tüm katılımciların sağ bacak hamstring ve kuadriseps izokinetik kuvvetlerinin yanı sıra hamstring / kuadriseps $(H / K, R)$ izokinetik kuvvet oranları, İsomed-2000 izokinetik dinamometre ile $60 \%$ sn açısal hızda ve beş tekrar olarak kaydedildi. Bu açısal hız birçok çalışmada olduğu gibi maksimum izokinetik gücü ölçmek için tercih edilen düşük açısal hızdır (Brown ve Whitehurst, 2003; Chan ve diğ., 1996; Costa ve diğ., 2013; Cramer ve diğ., 2004; Paoadopoulos ve diğ., 2005; Saliba ve Hrysomallis, 2001; Tuncer, 2000; Winke ve diğ., 2010; Zakas ve diğ., 2006).

\section{Verilerin Analizi}

Verilerin istatistiksel analizi SPSS 20 paket programı kullanılarak yapıldı. Verilerin normal dağılım gösterip göstermediğine Shapiro - Wilk testi ile bakıldı. Normal dağllım gösteren veriler için; ANOVA testi; normal dağıllım göstermeyen veriler için Kruskal Wallis testi uyguland. İstatistiksel anlamlılık düzeyi $\mathrm{p}<0.05$ olarak kabul edildi.

\section{BULGULAR}

Kadınların yaş ortalaması $21.4 \pm 1.6$ yıl, vücut ağırlı̆g $57.4 \pm 9.42 \mathrm{~kg}$, boy uzunluğu $167 \pm$ $15.2 \mathrm{~cm}$ 'dir. Erkeklerin yaş ortalaması $21.7 \pm 2.2$ y1l, boy uzunluğu $172 \pm 12.2 \mathrm{~cm}$ ve vücut ağırlı̆̆ı $70 \pm 11.7 \mathrm{~kg}$ ‘dır ( $<0.05)$.

İstatistiksel analiz önce tüm katılımcılar üzerinde daha sonra katılımcılar cinsiyete göre gruplandırılarak yapıldı. Araştırmaya alınan katılımcıların hamstring, kuadriseps ve hamstring/kuadriseps $(\mathrm{H} / \mathrm{K})$, (R) oranı değerlerinin yapılan egzersiz protokollerine bağlı olarak değişimi Grafik 1, Grafik 2 ve Grafik 3'te sunulmuştur. 
Songur, A., ve Çetin, E. (2018). Aktif statik germe ve farklı dinlenme aralıklarının izokinetik bacak kuvveti üzerine etkisi. Spor Bilimleri Araştırmaları Dergisi, 3(1), 85-96.

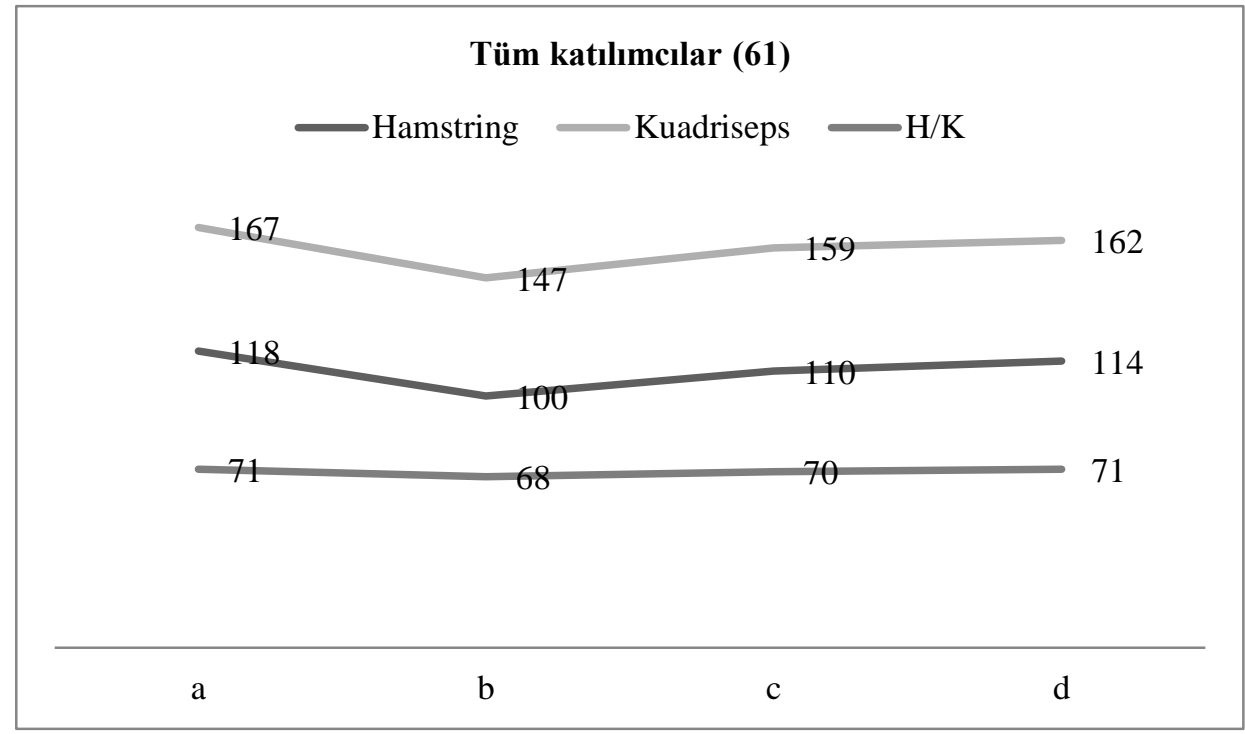

Hamstring: $\mathrm{a}-\mathrm{b}=+17.8 \mathrm{Nm}(\mathrm{p}=0.002), \mathrm{b}-\mathrm{d}=-13.7 \mathrm{Nm}(\mathrm{p}=0.018)$. Kuadriseps: $\mathrm{a}-\mathrm{b}=+19.6 \mathrm{Nm}(\mathrm{p}=0.006), \mathrm{b}-\mathrm{d}=-14.3$ $\mathrm{Nm}, \quad(\mathrm{p}=0.041) . \mathrm{H} / \mathrm{K},(\mathrm{R}) ;(\mathrm{p}=0.33)$.

Grafik 1: Tüm katılımcılar için protokoller arası kuvvet değişimi

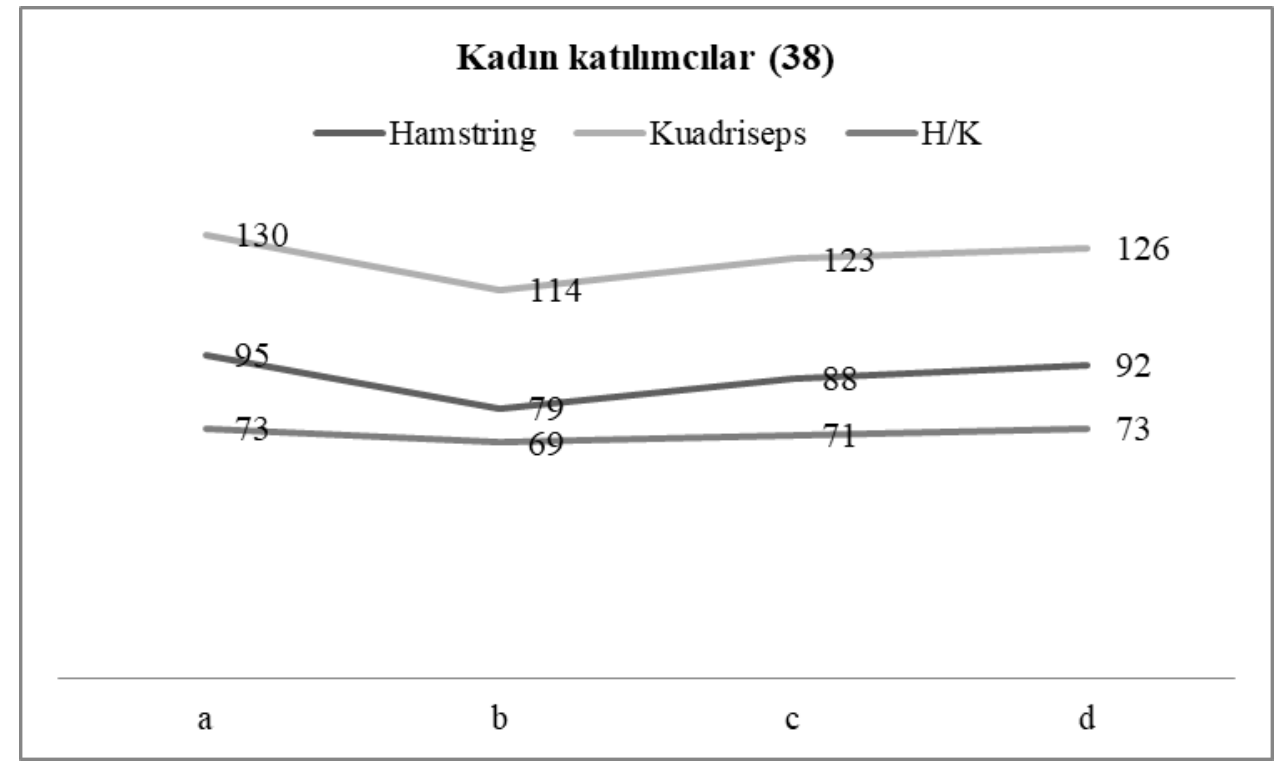

Hamstring: $\mathrm{a}-\mathrm{b}=+16.5 \mathrm{Nm},(\mathrm{p}=0.00) . \mathrm{b}-\mathrm{d}=-13.3 \mathrm{Nm},(\mathrm{p}=0.01)$. Kuadriseps: $\mathrm{a}-\mathrm{b}=+16.1 \mathrm{Nm}(\mathrm{p}=0.00), \mathrm{b}-\mathrm{d}=-11.5 \mathrm{Nm}$, $(\mathrm{p}=0.011) . \mathrm{H} / \mathrm{K},(\mathrm{R}) ;(\mathrm{p}=0.32)$.

Grafik 2: Kadın katılımcılar için protokoller arası kuvvet değişimi 
Songur, A., ve Çetin, E. (2018). Aktif statik germe ve farklı dinlenme aralıklarının izokinetik bacak kuvveti üzerine etkisi. Spor Bilimleri Araştırmaları Dergisi, 3(1), 85-96.

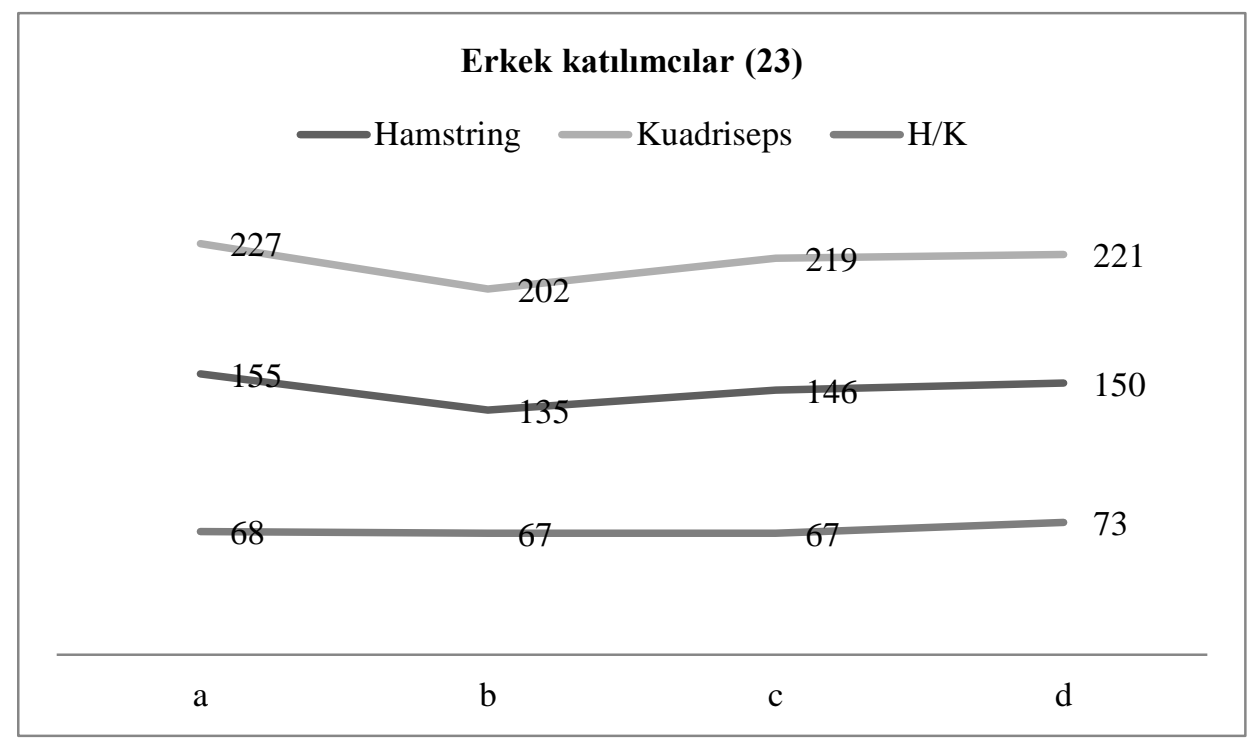

Hamstring: $\mathrm{a}-\mathrm{b}=+19.9(\mathrm{p}=0.008) . \mathrm{Nm} ; \mathrm{b}-\mathrm{d}=-15 \mathrm{Nm},(\mathrm{p}=0.034)$. Kuadriseps: $\mathrm{a}-\mathrm{b}=+25.3 \mathrm{Nm}(\mathrm{p}=0.008), \mathrm{b}-\mathrm{d}=-18.8 \mathrm{Nm}$, $(\mathrm{p}=0.044) . \mathrm{H} / \mathrm{K}(\mathrm{R}) ;(\mathrm{p}=0.69)$.

Grafik 3: Erkek katılımcılar için protokoller arası kuvvet değişimi

Veriler analiz edildiğinde tüm katılımcılar için yapılan ölçümlerde; a ile b ve b ile d ölçümleri arasında istatistiksel olarak anlamlı fark bulundu $(\mathrm{p}<0.05)$. Farkın oluşmasında $b$ ölçümünün a ve d ölçümlerine göre düşük olmasının etkili olduğu saptandı. Cinsiyetlere göre değerlendirildiğinde istatistiksel olarak aynı parelelde b ölçüm sonuçları anlamlı olarak düşük elde edildi. Diğer yandan $\mathrm{H} / \mathrm{K}$ oranı verileri tüm gruplar analiz edildiğinde protokoller arasında istatistiksel olarak anlamlı fark bulunmadı.

\section{TARTIŞMA ve SONUÇ}

Aerobik koşu, aktif statik germe, aktif statik germe sonrası 5 dakika ve 15 dakika dinlenme sonrasındaki izokinetik bacak kuvvet değerlerinin karşılaştırıldığ egzersizlerinin hemen sonrasında kuvvet kaybı yaşanabileceği görülmektedir. Nitekim, On altı erkek futbolcu üzerinde yapılan bir çalışmada da benzer bir sonuca ulaşılmış ve uzun süreli germe egzersizlerinin güç üretiminde olumsuz bir etkisi olduğu ve kuvvet performansında germe egzersizi uygulamaları ile düşüş gerçekleştiğini gözlemlemişlerdir (Zakas ve diğ., 2006). Germe egzersizlerinde uygulama süresi ve tekrar sayılarına odaklanan çalışma sayısı dikkat çekici oranda yüksektir. Başka bir çalışmada yirmi atletin diz ekstansiyon, fleksiyon ve plantar fleksiyon kaslarının üçüne uygulanan farklı sürelerde (2x15 sn, 4x15 sn, 6x15 sn) statik germe egzersizlerinin dikey sıçrama performansına olan etkisi araştırılmış, 6 set 15 sn uygulamasının dikey sıçrama performansında azalmaya neden olduğu diğer protokollerin ise bir değişime neden olmadığı sonucuna ulaşılmıştır (Robbins ve Scheuermann, 2008). Bu bilgiler 1şı̆̆ında statik germe egzersizlerinin süresi ve tekrar sayılarının oldukça önemli olduğu ve bu etkilerin incelenmesinde fayda görülebileceği kanısıyla yapılan diğer çalışmalar egzersizin süresinin ve tekrar sayısının artmasının performansı ne şekilde etkilediği konusuna odaklanmıştır. Aynı sürede fakat farklı tekrar sayısında yapılan statik germe egzersizlerinin izokinetik kuvvet üzerine etkisinin araştırıldığ çalışmada 3 tekrar 15 sn (45 sn) ve 20 tekrar 15 sn (300 sn) statik germe uygulanmış, çalışma 
sonucunda 3 tekrar uygulaması izokinetik kuvvette bir değişiklik yaratmazken, 20 tekrar uygulaması tüm açılarda izokinetik kuvveti olumsuz olarak etkilemiştir (Zakas ve diğ., 2006). Yarı profesyonel on dört futbolcunun dahil edildiği ve statik germe süresinin(1x30sn, 10x30sn, 16x30sn) baskın bacak diz ekstansiyonu maksimum izokinetik tork üretimi üzerindeki etkisinin farklı açısal hızlardaki $(60,90,150,210$ ve 270) değişiminin incelendiği bir çalışmada tek set 30 sn statik germenin tork üretiminde herhangi bir değişim yaratmadığı fakat 10 set ve 16 set yapılan statik germenin tork üretiminde düşüşe neden olduğu sonucuna varılmıştır (Zakas ve diğ., 2006b). Yüz katılımcı üzerinde yapılan bir çalışmada, statik germenin ısınmanın içine katıldığında dikey sıçrama performansında belirgin düşüş olduğu gözlenmiş̧tir (Açıkgöz ve diğ., 2010). Hamstring kasına uygulanan 30 sn ve 60 sn süreli statik germe hareketinin akut etkilerinin karşılaştırıldığ bir başka çalışmada da her iki germe süresinin de kasın boyunda anlamlı değişiklik yarattı̆̆ olmadığı, öbür taraftan hamstring kasının ürettiği kuvvetin 60 sn germe sonrası anlamlı şekilde azaldığ $1,30 \mathrm{sn}$ ve kontrol grubunda ise anlamlı bir fark olmadığı tespit edilmiştir (Ogura ve diğ., 2007).

Germe egzersizleri ve kuvvet parametresi ilişkilerinin değerlendirildiği çalışmalara bakıldığında, statik germe egzersizlerinin izokinetik bacak gücünü etkili bir şekilde azalttığı kanıtlanmıştır. On erkek ve beş kadın ile yapılan bir çalışmada, 15 dakika süren statik germenin maksimum izokinetik diz ekstansiyon tork üretimi üzerindeki etkisinin hareketin hızına bağlı değişimi incelenmiş ve uygulanan statik germenin düşük hızdaki hareketler sırasında tork üretiminde düşüşe sebep olduğu ancak yüksek hızdaki hareketlerde bir değişim yaratmadığı sonucuna varılmıştır (Nelson ve diğ., 2001). On iki kuvvet antrenmanı yapan erkek katılımcı üzerinde statik, dinamik ve PNF germe tekniklerinin maksimal kuvvet, tekrar sayısı ve toplam volüm üzerine olan etkisinin araştırıldığı çalışmada ise, tüm germe tiplerinin ROM (range of motion) da artış sağladığ 1 MT (1 maksimum tekrar) leg pres değerlerinin yalnızca PNF germe sonrasında düşüş gösterdiği, tekrar sayısında ve toplam volümde ise tüm germe tipleri sonrasında düşüş yaşandığı görülmüş bu nedenle dirençli antrenman sırasında germe egzersizlerinin yapılmaması gerektiği sonucuna varılmıştır (Barosso ve diğ., 2012). Miyahara ve arkadaşları (2013) PNF germe ve statik germenin maksimum istemli kasılma üzerindeki etkilerinin karşılaştırılması amacıyla yaptıkları çalışmada on üç erkek üniversite öğrencisine 3 ayrı günde 3 farklı protokol (PNF, statik germe, kontrol) uygulamış, sonrasında kalça fleksiyonu eklem hareket açıklığı ve maksimum istemli diz fleksiyonu ölçümleri elektromiyografi (EMG) ile almışlardır. Çalışmanın sonucunda PNF in ROM'u arttırdığını öbür yandan statik germenin ve PNF germenin maksimal izometrik kuvveti düşürdügünü bildirmişlerdir. Statik germenin maksimum konsantrik izokinetik bacak ekstansiyon güç üretimine etkisinin araştırıldığı bir diğer çalışmada ise, statik germe sonrası, hem germe uygulanan baskın taraf hem de germe uygulanmayan karşı taraf bacak ekstansiyon kuvvetinde, 60 ve 240 açısal hızların her ikisinde de istatistiksel olarak anlamlı düşüş olduğu sonucuna varmışlardır (Cramer ve diğ., 2004). Bu çalışmalara paralel olarak yirmi iki kadın üzerinde yapılan ve statik germenin hamstring ve kuadriseps maksimal izokinetik kuvveti ve hamstring kuadriseps izokinetik kuvvet oranı üzerine etksinin 60 ve $180(\%)$ hızda araştırıldığı bir çalışmada statik germenin hamstring ve kuadriseps oranlarını olumsuz yönde etkileyebileceği sonucuna varılmıştır (Costa ve diğ., 2013). 
Çalışmanın sonuçları ve literatür bilgileri ışığında, farklı süreler ya da tekrar sayılarına bağlı olarak yapılan statik germenin kuvvete olduğu gibi farklı performanslar üzerine de olumsuz etkisinin olduğu görülmekle beraber etkinin ne kadar sürdüğü ve değişimi konusunda yeterince çalışmaya rastlanmamıştır. Dolayısıyla araştırmada ana başlık olarak statik germe egzersizi sonrasında geçen farklı sürelere bağlı olarak etkilenmenin boyutu saptanmaya çalışılmıştır. Statik germe hemen sonrası oluşan kuvvet kaybının en fazla olduğu ve kas kuvvetinin beşinci ve on beşinci dakikalarda dinlenmeye bağlı olarak giderek toparlanmasına rağmen statik germe öncesi kuvvet değerlerine hala tam olarak geri dönemediği tespit edilmiştir. Kuvvet kaybıyla direk ilişkili olmasa da az sayıda rastlanan çalışmalarda da statik germenin olumsuz etkilerinin 15-20 dakika sürebildiği bildirilmiştir (Bradley ve diğ., 2007; Ogura ve diğ., 2007; Nelson ve diğ., 2001). On sekiz erkek üniversite öğrencisi üzerinde, farklı germe tiplerinin (statik, balistik, PNF) dikey sıçrama performansı üzerine etkilerinin karşılaştırıldığı çalışmada, katılımcılara uygulanan her biri 10 dakikalık farklı germe protokollerini takiben 5, 15, 30, 45 ve 60 dakika sonra dikey siçrama ölçümleri kaydedilmiştir. Sonuç olarak statik (\%4) ve PNF (\%5.1) germe sonrasında dikey sıçrama yüksekliğinde anlamlı düşüş olduğu saptanmıştır. Öbür taraftan statik ve PNF germe tiplerinden sonraki dikey sıçrama yüksekliğindeki bu düşüşler ancak 15 dakika sonra eski seviyesine geri dönebilmektedir. Bu nedenle patlayıcı kuvvet gerektiren bir hareketten önce PNF veya statik germe yapılmaması gerektiği sonucuna varılmıştır (Bradley ve diğ., 2007).

Benzer şekilde kadın ve erkek ölçümlerinde de istatistiksel olarak anlamlı fark olduğu ve bu farkın cinsiyet ayrımı yapılmadan alınan sonuçlar gibi a ile $b$ ve $b$ ile $d$ ölçümleri arasındaki anlamlı farktan kaynaklandığı görülmüştür. Kadın ve erkek ölçümlerindeki H/K (R) değeri analiz edildiğinde yine anlamlı bir fark bulunamamıştır. Elde edilen analiz sonuçları daha önce yapılan araştırmalarda ağırlık kazanan, statik germenin kas kuvvetini olumsuz etkilediği görüşünü desteklemektedir. Ancak bir diğer ve çalışma açısından en önemli sonuç ise; statik germenin izokinetik kuvvet üzerindeki bu olumsuz etkisinin en az on beş dakika azalarak devam ettiğidir. Performanstaki bu düşüşün sakatlanma riskini de beraberinde getirebileceği dikkatle değerlendirilmelidir. Ayrıca birbirlerinin antagonisti olan hamstring ve kuadriseps kas gruplarının her ikisinde de izokinetik kuvvet düşüşü kaydedilmiş olması, dinlenmenin yanı sıra, uygulanan germenin her iki antagonist kasa ve hatta kontralateral vücut bölgesine uygulanmasının, akut kas kuvvet dengesizliği oluşmaması açısından daha isabetli olacağı sonucunu doğurmaktadır. Sporcuların isınma periyotlarına dahil ettikleri statik germe egzersizlerini takiben, en az on beş dakika dinlendikten sonra yüksek performans gerektiren bir aktiviteye başlamaları gerektiği sonucuna varılabilir.

$\mathrm{Bu}$ çalışma, germe egzersizlerinin kas kuvveti üzerindeki süreye bağlı negatif etkileri hakkında ayrıntılı bir gözlem sağlamaktadır. Sunulan sonuçları dikkate alarak; statik germe egzersizinden sonra, yüksek performans gerektiren herhangi bir sportif aktiviteye başlamadan önce sporculara dinlenme zamanı önerilir. Bu çalışmada sunulan detaylı gözlemler ve veriler, sporcuların performans artırımı yapmak ve yüksek yoğunluklu kas aktivitelerinde yaralanmaları önlemek için kullanılabilir. Geniş ve önemli pratik uygulamalara sahip olan bu çalışma, laboratuvar ve saha uygulayıcısı arasındaki boşluğu kapatmaktadır. Farklı açısal hız, farklı egzersiz ve dinlenme sürelerinde daha fazla katılımcıyla yapılacak ileri çalışmalar önerilir. 
Songur, A., ve Çetin, E. (2018). Aktif statik germe ve farklı dinlenme aralıklarının izokinetik bacak kuvveti üzerine etkisi. Spor Bilimleri Araştırmaları Dergisi, 3(1), 85-96.

\section{KAYNAKLAR}

Açıkgöz, A., Gelen, E., Saygın, Ö., Karacabey, K., Yıldız, S. (2010). Acute Effects Of Warm-up Methods On JumpPerformance In Athletes With Different Body Fat Percentages. 11th International Sports Science Congress 10-12 November Abstract Book. s.100-102.

Appleton, B. (1998). Stretching and flexibility Flexibility-Everything you never wanted to know. Massachusetts Institute of Technology website. http://www.bradapp.com/docs/rec/stretching/ Erişim tarihi: 14.03 .2018

Ardıç, F. (2014). Egzersiz reçetesi. Türk Fiz Tip Rehab Derg, 60 (Özel Sayı 2): 9-14. DOI: $10.5152 /$ tftrd.2014.33716.

Barroso, R., Tricoli, V., dos Santos Gil, S., Ugrinowitsch, C., \& Roschel, H. (2012). Maximal strength, number of repetitions, and total volume are differently affected by static, ballistic, and proprioceptive neuromuscular facilitation stretching. The Journal of Strength \& Conditioning Research, 26(9), 24322437.

Bradley, P.S., Peter, D. O., \& Matthew, D.P. (2007). The effect of static, ballistic, and proprioceptive neuromuscular facilitation stretching on vertical jump performance. The Journal of Strength \& Conditioning Research 21(1), 223-22.

Brown, L.E., \& Whitehurst, M. (2003). The effect of short-term isokinetic training on force and rate of velocity development. Journal of Strength and Conditioning Research, 17(1), 88-94.

Carvalho, F. L., Prati, J. E. L. R., de Alencar Carvalho, M. C. G., \& Dantas, E. H. M. (2009). Efeitos agudos do alongamento estático e da facilitaçao neuromuscular proprioceptiva no desempenho do salto vertical de tenistas adolescentes. Fitness \& performance journal, 8(4), 264-268. Doi:10.3900/fpj.8.4.264.p.

Chan, K. M., Maffulli, N., \& Korkia, P. (1996). Principles and practice of isokinetics in sports medicine and rehabilitation (pp. 107-186). Hong Kong: Williams \& Wilkins.

Costa, P. B., Ryan, E. D., Herda, T. J., Walter, A. A., Defreitas, J. M., Stout, J. R., \& Cramer, J. T. (2013). Acute effects of static stretching on peak torque and the hamstrings to quadriceps conventional and functional ratios. Scandinavian journal of medicine \& science in sports, 23(1), 38-45.

Cramer, J. T., Beck, T. W., Housh, T. J., Massey, L. L., Marek, S. M., Danglemeier, S., \& Egan, A. D. (2007). Acute effects of static stretching on characteristics of the isokinetic angle-torque relationship, surface electromyography, and mechanomyography. Journal of sports sciences, 25(6), 687-698.

Cramer, J. T., Housh, T. J., Johnson, G. O., Miller, J. M., Coburn, J. W., \& Beck, T. W. (2004). Acute effects of static stretching on peak torque in women. The Journal of Strength \& Conditioning Research, 18(2), 236241.

Fredericson, M., White, J. J., MacMahon, J. M., \& Andriacchi, T. P. (2002). Quantitative analysis of the relative effectiveness of 3 iliotibial band stretches. Archives of physical medicine and rehabilitation, 83(5), 589592.

Kay, A. D., Blazevich, A. J. (2012). Effect of acute static stretch on maximal muscle performance: a systematic review. Medicine \& Science in Sports \& Exercise, 44(1), 154-164.

Kokkonen, J., Nelson, A.G., \& Cornwell, A. (1998). Acute muscle stretching inhibits maximal strength performance. Research quarterly for exercise and sport, 69(4), 411-415.

McBride, J. M., Deane, R., \& Nimphius, S. (2007). Effect of stretching on agonist-antagonist muscle activity and muscle force output during single and multiple joint isometric contractions. Scandinavian journal of medicine \& science in sports, 17(1), 54-60. 
Songur, A., ve Çetin, E. (2018). Aktif statik germe ve farklı dinlenme aralıklarının izokinetik bacak kuvveti üzerine etkisi. Spor Bilimleri Araştırmaları Dergisi, 3(1), 85-96.

Miyahara, Y., Naito, H., Ogura, Y., Katamoto, S., \& Aoki, J. (2013). Effects of proprioceptive neuromuscular facilitation stretching and static stretching on maximal voluntary contraction. The Journal of Strength \& Conditioning Research, 27(1), 195-201.

Nelson, A. G. \& Kokkonen, J. (2007). Stretching anatomy (p. 147). Chicago: Human kinetics.

Nelson, A. G., Driscoll, N. M., Landin, D. K., Young, M. A., \& Schexnayder, I. C. (2005). Acute effects of passive muscle stretching on sprint performance. Journal of sports sciences, 23(5), 449-454.

Nelson, A. G., Gulllory, I. K., Cornwell, A., \& Kokkonen, J. (2001). Inhibition of maximal voluntary isokinetic torque production following stretching is velocity-specific. The Journal of Strength \& Conditioning Research, 15(2), 241-246.

Ogura, Y., Miyahara, Y., Naito, H., Katamoto, S., \& Aoki, J. (2007). Duration of static stretching influences muscle force production in hamstring muscles. Journal of Strenght and Conditioning Research, 21(3), 788- 792.

Paoadopoulos, G., Siatras, T. H., \& Kellis, S. (2005). The effect of static and dynamic stretching exercises on the maximal isokinetic strength of the knee extensors and flexors. Isokinetics and exercise science, 13(4), 285-291.

Power, K., Behm, D., Cahill, F., Carroll, M., \& Young, W. (2004). An acute bout of static stretching: effects on force and jumping performance. Medicine \& Science in Sports \& Exercise, 36(8), 1389-1396.

Robbins, J. W., Scheuermann, B. W. (2008). Varying amounts of acute static stretching and its effect on vertical jump performance. The Journal of Strength \& Conditioning Research, 22(3), 781-786.

Rodenburg, J. B., Steenbeek, D., Schiereck, P., \& Bär, P. R. (1994). Warm-up, stretching and massage diminish harmful effects of eccentric exercise. International Journal of sports medicine, 15(7), 414-419.

Rubini, E. C., Costa, A. L., \& Gomes, P. S. (2007). The effects of stretching on strength performance. Sports medicine, 37(3), 213-224.

Sady, S. P., Wortman, M., \& Blanke, D. (1982). Flexibility training: ballistic, static or proprioceptive neuromuscular facilitation? Archives of physical medicine and rehabilitation, 63(6), 261-263.

Saliba, L., \& Hrysomallis, C. (2001). Isokinetic strength related to jumping but not kicking performance of Australian footballers. Journal of Science and Medicine in Sport, 4(3), 336-347.

Sekir, U., Arabaci, R., Akova, B., \& Kadagan, S. M. (2010). Acute effects of static and dynamic stretching on leg flexor and extensor isokinetic strength in elite women athletes. Scandinavian journal of medicine \& science in sports, 20(2), 268-281.

Shellock, F. G., \& Prentice, W. E. (1985). Warming-up and stretching for improved physical performance and prevention of sports-related injuries. Sports Medicine, 2(4), 267-278

Shrier, I. (2004). Does stretching improve performance?: A systematic and critical review of the literature. Clinical journal of sport medicine, 14(5), 267-273.

Siatras, T., Papadopoulos, G., Mameletzi, D., Gerodimos, V., \& Kellis, S. (2003). Static and dynamic acute stretching effect on gymnasts' speed in vaulting. Pediatric Exercise Science, 15(4), 383-391.

Siatras, T. A., Mittas, V. P., Mameletzi, D. N., \& Vamvakoudis, E. A. (2008). The duration of the inhibitory effects with static stretching on quadriceps peak torque production. The Journal of Strength \& Conditioning Research, 22(1), 40-46.

Smith, C. A. (1994). The warm-up procedure: to stretch or not to stretch. A brief review. Journal of Orthopaedic and Sports Physical Therapy, 19(1), 12-17.

Tuncer, S. (2000). Fonksiyonel Değerlendirmede İzokinetik Sistem Kullanımı. Fiziksel Tip ve Rehabilitasyon Cilt 1. Beyazova M, Kutsal YG (Editörler). Ankara: Güneş Kitapevi. 
Songur, A., ve Çetin, E. (2018). Aktif statik germe ve farklı dinlenme aralıklarının izokinetik bacak kuvveti üzerine etkisi. Spor Bilimleri Araştırmaları Dergisi, 3(1), 85-96.

Unick, J., Kieffer, H. S., Cheesman, W., \& Feeney, A. (2005). The acute effects of static and ballistic stretching on vertical jump performance in trained women. The Journal of Strength \& Conditioning Research, 19(1), 206-212.

Walker, B. (2013). The anatomy of stretching: your illustrated guide to flexibility and injury rehabilitation. North Atlantic Books.

Winke, M. R., Jones, N. B., Berger, C. G., \& Yates, J. W. (2010). Moderate static stretching and torque production of the knee flexors. The Journal of Strength \& Conditioning Research, 24(3), 706-710.

Young, W. B., \& Behm, D. G. (2003). Effects of joggingning, static stretching and practice jumps on explosive force production and jumping performance. Journal of Sports Medicine and Physical Fitness, 43(1), 2127.

Zakas, A., Doganis, G., Galazoulas, C., \& Vamvakoudis, E. (2006). Effect of acute static stretching duration on isokinetic peak torque in pubescent soccer players. Pediatric Exercise Science, 18(2), 252-261.

Zakas, A., Doganis, G., Papakonstandinou, V., Sentelidis, T., \& Vamvakoudis, E. (2006). Acute effects of static stretching duration on isokinetic peak torque production of soccer players. Journal of Bodywork and Movement Therapies, 10(2), 89-95. 